\title{
KAJIAN TERHADAP TINGKAT PEMERATAAN PENDIDIKAN MENGGUNAKAN ANALISIS BIPLOT KLASIK DAN BIPLOT KEKAR
}

\author{
Ni Luh Ardila Kusumayanti ${ }^{\S 1}$, I Komang Gde Sukarsa ${ }^{2}$, Tjokorda Bagus Oka ${ }^{3}$,
} I Putu Eka Nila Kencana ${ }^{4}$

\footnotetext{
${ }^{1}$ Jurusan Matematika, F.MIPA - Universitas Udayana [Email: ardillakusumayanti@gmail.com ${ }^{1}$ ]

${ }^{2}$ Jurusan Matematika, F.MIPA - Universitas Udayana [Email: sukarsakomang @yahoo.com²]

${ }^{3}$ Jurusan Matematika, F.MIPA - Universitas Udayana [Email: tjokordabagusoka@gmail.com³

${ }^{4}$ Jurusan Matematika, F.MIPA - Universitas Udayana [Email: i.putu.enk@gmail.com ${ }^{4}$ ]

${ }^{\S}$ Corresponding Author
}

\begin{abstract}
The aim of this research is to find the better from classical and robust biplot in determine dominant indicators of educational equity in Bali, NTB and NTT Provinces. This research based on secondary data obtain from Central Bureau of Statistics for year 2012/2013. Educational equity was portraited by Classical and Robust Biplot. The results of this research showed Robust Biplot is better method which goodness of fit is 90,64\% meanwhile Classical Biplot as much as 83,62\%. The Robust Biplot showed Students- Junior or Islamic Middle School Ratio and Students-Senior or Islamic High School were dominant indicators to educational equity in Bali, NTB and NTT Provinces.
\end{abstract}

Keywords: educational equity, education indicators, classical biplot, robust biplot.

\section{PENDAHULUAN}

Pendidikan merupakan salah satu kebutuhan yang penting dalam kehidupan sehari-hari guna meningkatkan mutu kehidupan dan meningkatkan martabat manusia. Seluruh lapisan masyarakat berhak mendapat kesamaan kesempatan dalam memperoleh pendidikan. Salah satu upaya pemerintah Indonesia untuk memenuhi hak setiap warga negara dalam memperoleh layanan pendidikan yaitu menetapkan program wajib belajar sembilan tahun.

Dari ulasan di atas, maka dilakukan penelitian untuk mengetahui pemerataan pendidikan pada setiap Kabupaten/Kota di Bali, Nusa Tenggara Barat (NTB), dan Nusa Tenggara Timur (NTT) dengan menggunakan analisis biplot klasik dan biplot kekar.

Tujuan penelitian ini adalah untuk mengetahui metode yang lebih baik (biplot klasik atau biplot kekar) dan mengetahui indikator pendidikan yang dominan terhadap pemerataan pendidikan di Bali, NTB dan NTT dilihat dari metode yang terbaik.

Analisis biplot merupakan analisis multivariat yang menyajikan secara simultan objek pengamatan dan peubah dalam dimensi dua (Jolliffe [1]). Analisis biplot didasarkan pada Singular Value Decomposition (SVD) matriks data yang ditulis dengan:

$$
{ }_{\mathrm{n}} \mathbf{X}_{\mathrm{p}}={ }_{\mathrm{n}} \mathbf{U}_{\mathrm{r}} \cdot{ }_{\mathrm{r}} \mathbf{L}_{\mathrm{r}} \cdot{ }_{\mathrm{p}} \mathbf{A}_{\mathrm{r}}^{\mathrm{T}}
$$

Matriks $\mathbf{U}$ dan $\mathbf{A}$ merupakan matriks dengan kolom ortonormal, yang masing-masing merupakan vektor eigen dari matriks $\mathbf{X}^{\mathbf{T}} \mathbf{X}$ dan matriks $\mathbf{X X}^{\mathbf{T}}$. Matriks $\mathbf{L}$ merupakan matriks diagonal yang diagonal utamanya terdiri dari akar nilai eigen matriks $\mathbf{X}^{\mathbf{T}} \mathbf{X}$.

Pencilan merupakan suatu data yang menyimpang cukup jauh dari variabilitas data asalnya (Filzmoser [2]). Identifikasi pencilan pada data multivariat didasarkan pada kuadrat jarak Mahalanobis, yang didefinisikan (Johnson \& Wichern [3]):

$$
\mathrm{MD}_{\mathrm{i}}^{2}=\left[\mathbf{x}_{\mathbf{i}}-\overline{\mathbf{x}}\right]^{\mathrm{T}} \mathbf{S}^{-\mathbf{1}}\left[\mathbf{x}_{\mathbf{i}}-\overline{\mathbf{x}}\right]
$$


jika $\quad \mathrm{MD}_{\mathrm{i}}^{2}>\chi_{p ; 1-\alpha}^{2} \quad(\alpha=0,975)$ maka pengamatan tersebut dapat dinyatakan sebagai data pencilan.

Penggunaan jarak mahalanobis untuk mengidentifikasi pencilan tidak maksimal jika data mengandung lebih dari satu pengamatan pencilan. Hal ini muncul akibat adanya pengaruh Masking dan Swamping (Rousseeuw \& Driessen [4]). Masking maupun Swamping dapat diatasi dengan penduga kekar, salah satunya adalah Minimum Covariance Determinant (MCD), yang didefinisikan:

$$
\mathrm{RD}_{\mathrm{i}}^{2}=\left[\mathbf{x}_{\mathbf{i}}-\mathbf{t}_{\mathbf{m c d}}\right]^{\mathrm{T}} \mathbf{C}_{\mathbf{m c d}}^{-\mathbf{1}}\left[\mathbf{x}_{\mathbf{i}}-\mathbf{t}_{\mathbf{m c d}}\right]
$$

dengan $R D_{i}$ merupakan jarak kekar pengamatan ke-i; $\mathbf{x}_{i}$ merupakan data pengamatan ke-i; $\mathbf{t}_{\text {mcd }}$ dan $\mathbf{C}_{\mathbf{m c d}}$ menyatakan vektor rataan dan matriks kovarians yang diduga dengan metode MCD.

Analisis biplot kekar adalah suatu pendekatan yang dilakukan dengan menduga nilai eigen dan vektor eigen kiri (U) dan kanan (A) sehingga hasil dugaan tersebut tahan terhadap data pencilan (Hawkins et al. [5]). Salah satu metode yang digunakan untuk menduga rataan dan matriks kovarians kekar adalah menggunakan metode MCD.

Penduga MCD dengan algoritma FastMCD dilakukan dengan langkah-langkah, yaitu: ambil himpunan bagian dari matriks $\mathrm{X}$ secara acak, dimisalkan himpunan bagian tersebut sebagai $\mathrm{H}_{1}$ dengan jumlah elemen sebanyak $h$, dimana $h=\frac{\mathrm{n}+\mathrm{p}+1}{2}$. Hitung vektor rata-rata $\mathbf{t}_{\mathbf{1}}$ dan matriks kovarians $\mathbf{C}_{\mathbf{1}}$ dari $\mathrm{H}_{1}$ dengan persamaan $\quad \mathbf{t}_{\mathbf{m c d}}=\frac{1}{\mathrm{~h}} \sum_{\mathrm{i}=1}^{\mathrm{h}} \mathbf{x}_{\mathrm{i}} \quad$ dan $\mathbf{C}_{\mathbf{m c d}}=\frac{1}{\mathrm{~h}-1} \sum_{\mathrm{i}=1}^{\mathrm{h}}\left[\mathbf{x}_{\mathbf{i}}-\mathbf{t}\right]^{\mathrm{T}}\left[\mathbf{x}_{\mathbf{i}}-\mathbf{t}\right] . \quad$ Hitung determinan matriks kovarians $\mathbf{C}_{\mathbf{1}}$, jika $\left|\mathbf{C}_{\mathbf{1}}\right|=0$ maka berhenti. Jika tidak, maka hitung jarak mahalanobis

$D_{i}=\sqrt{\left[x_{i}-t_{1}\right]^{T} \mathbf{C}_{1}{ }^{-1}\left[x_{i}-t_{1}\right]}, i=1,2, \ldots, n$ dan urutkan jarak mahalanobis dari urutan terkecil hingga terbesar. Selanjutnya ambil elemen dari $h$ pengamatan dengan jarak terkecil untuk menjadi elemen himpunan bagian $\mathrm{H}_{2}$, lakukan langkah-langkah sebelumnya sehingga diperoleh $\operatorname{det}\left(\mathrm{C}_{\mathrm{n}+1}\right) \leq \operatorname{det}\left(\mathrm{C}_{\mathrm{n}}\right)$. Selanjutnya berdasarkan anggota $h$ tersebut, data kemudian diboboti, yaitu sesuai dengan: $\mathrm{w}_{\mathrm{i}}\left\{\begin{array}{c}1, \mathrm{RD}_{\mathrm{i}}^{2}<\chi_{p ; 1-\alpha}^{2} . \text { Selanjutnya berdasarkan } \\ 0, \text { lainnya }\end{array}\right.$ pembobot $\mathrm{w}_{\mathrm{i}}$, penduga Fast-MCD adalah $\mathbf{t}_{\mathrm{MCD}}=\frac{\sum_{\mathrm{i}=1}^{\mathrm{n}} \mathrm{w}_{\mathrm{i}} \mathbf{x}_{\mathrm{i}}}{\sum_{\mathrm{i}=1}^{\mathrm{n}} \mathrm{w}_{\mathrm{i}}}$ dan

$$
\mathbf{C}_{\mathrm{MCD}}=\frac{\sum_{\mathrm{i}=1}^{\mathrm{n}} \mathrm{w}_{\mathrm{i}}\left[\mathbf{x}_{\mathrm{i}}-\mathbf{t}_{\mathrm{mcd}}\right]^{\mathrm{T}}\left[\mathbf{x}_{\mathrm{i}}-\mathbf{t}_{\mathrm{mcd}}\right]}{\sum_{\mathrm{i}=1}^{\mathrm{n}} \mathrm{w}_{\mathrm{i}}-1} .
$$

\section{METODE PENELITIAN}

Penelitian ini menggunakan data sekunder yang diperoleh dari Badan Pusat Statistika Provinsi Bali, NTB, dan NTT tahun 2012/2013. Data yang digunakan adalah data Angka Partisipasi Kasar (APK), Angka Partisipasi Murni (APM), Rasio Siswa per Guru (R-S/G), Rasio Siswa per Sekolah (R-S/Sk) dan Rasio Guru per Sekolah (R-G/Sk) menurut jenjang pendidikan dan Kabupaten/Kota (BPS [6]).

Langkah pertama dalam penelitian ini adalah melakukan penyiapan data. Peubah yang digunakan pada penelitian ini berdimensi 15 dan memiliki satuan pengukuran yang sama sehingga data asal cukup dikoreksi dengan masing-masing nilai tengahnya.

Selanjutnya dilakukan identifikasi pencilan yang didasarkan pada kuadrat jarak mahalanobis. Penggunaan jarak mahalanobis tidak maksimum apabila terdapat lebih dari satu pengamatan pencilan. Hal tersebut dikarenakan adanya pengaruh Masking dan Swamping, oleh sebab itu dilakukan perhitungan terhadap jarak kekarnya dengan menggunakan penduga MCD.

Langkah selanjutnya dilakukan analisis biplot klasik yaitu dengan mencari SVD yang akan memperoleh vektor eigen dan nilai eigen, kemudian hasil tersebut disubstitusikan sehingga memperoleh matriks GH dengan $\alpha=$ 0 yang memberikan informasi mengenai koordinat-koordinat dimensi peragaan biplot.

Analisis biplot kekar dilakukan sesuai dengan langkah-langkah algoritma Fast-MCD. Berdasarkan algoritma Fast-MCD akan diperoleh $\mathbf{t}_{\mathrm{MCD}}$ dan $\mathbf{C}_{\mathrm{MCD}}$ terboboti. Kemudian dicari SVD kekar, dimana langkah-langkahnya sama dengan analisis biplot klasik. 


\section{HASIL DAN PEMBAHASAN}

Data yang telah dikoreksi dengan nilai tengahnya kemudian diolah dengan menggunakan metode SVD akan memperoleh nilai eigen dari biplot klasik dan biplot kekar. Secara terurut nilai eigen dan ukuran kesesuaian biplot klasik dan biplot kekar ditampilkan pada Tabel 1.

Tabel 1. Nilai Eigen dan Persentase Kumulatif Biplot Klasik dan Biplot Kekar

\begin{tabular}{|c|c|c|c|}
\hline \multicolumn{2}{|c|}{ Biplot Klasik } & \multicolumn{2}{c|}{ Biplot Kekar } \\
\hline $\begin{array}{c}\text { Nilai } \\
\text { Eigen }\end{array}$ & $\begin{array}{c}\text { Persentase } \\
\text { Kumulatif }\end{array}$ & $\begin{array}{c}\text { Nilai } \\
\text { Eigen }\end{array}$ & $\begin{array}{c}\text { Persentase } \\
\text { Kumulatif }\end{array}$ \\
\hline 17891.149 & 0.620 & 21593.710 & 0.587 \\
\hline 6255.149 & 0.836 & 11751.730 & 0.906 \\
\hline 3548.227 & 0.959 & 2077.504 & 0.963 \\
\hline 433.665 & 0.974 & 545.944 & 0.978 \\
\hline 227.901 & 0.982 & 385.599 & 0.988 \\
\hline 198.910 & 0.989 & 228.209 & 0.994 \\
\hline 137.181 & 0.994 & 115.470 & 0.998 \\
\hline 56.364 & 0.996 & 38.364 & 0.999 \\
\hline 37.647 & 0.997 & 25.529 & 0.999 \\
\hline 33.167 & 0.998 & 10.619 & 0.999 \\
\hline 32.170 & 0.999 & 8.041 & 0.999 \\
\hline 14.409 & 0.999 & 3.649 & 0.999 \\
\hline 7.124 & 0.999 & 2.291 & 0.999 \\
\hline 2.221 & 0.999 & 0.626 & 0.999 \\
\hline 0.444 & 1.000 & 0.171 & 1.000 \\
\hline
\end{tabular}

Berdasarkan Tabel 1 dapat ditampilkan bahwa biplot klasik mampu menjelaskan sebesar 83,62\%, sementara biplot kekar mampu menjelaskan sebesar $90,64 \%$ dari keseluruhan data dalam dimensi dua.

Penggambaran biplot klasik dan biplot kekar ditampilkan hingga dimensi dua, sehingga hanya digunakan dua skor komponen utama pertama dari matriks $\mathbf{G}$ dan $\mathbf{H}$. Plot hasil analisis biplot klasik dan biplot kekar dapat ditunjukkan pada Gambar 3 dan Gambar 4.

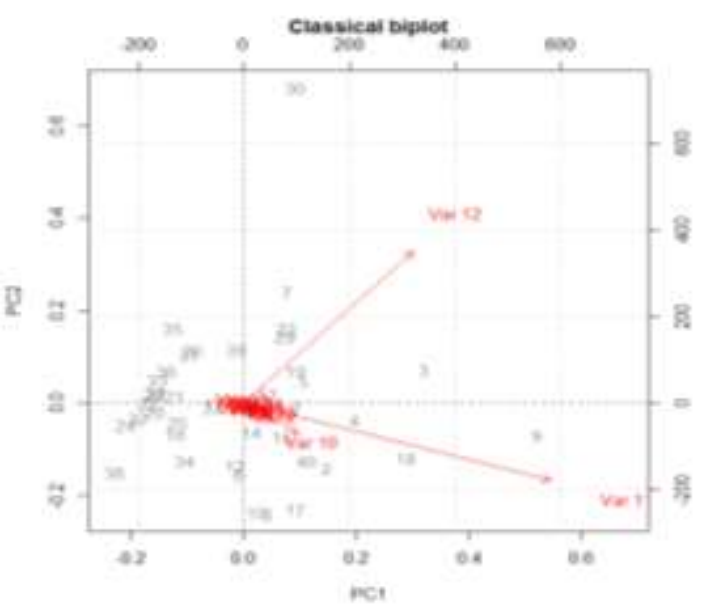

Gambar 3. Analisis Biplot Klasik

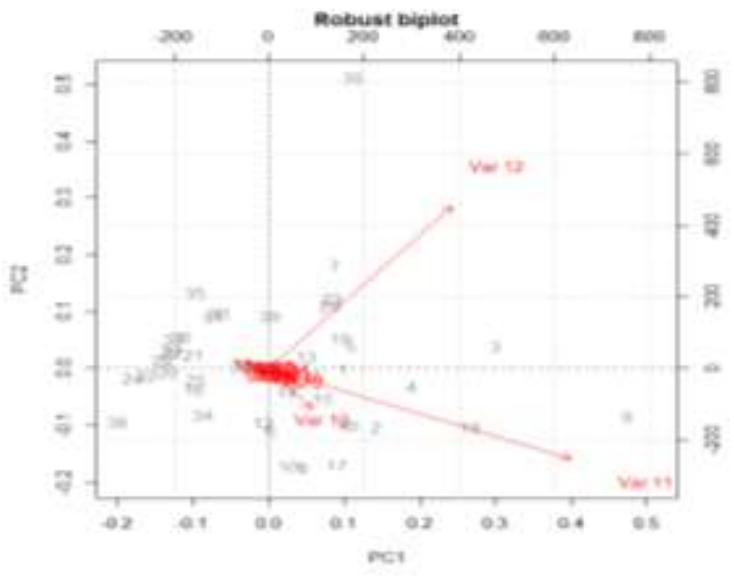

Gambar 4. Analisis Biplot Kekar

Kedekatan antar objek dalam analisis biplot dapat diketahui dengan melihat jarak Euclid antar objek yang satu dengan yang lainnya. Semakin kecil nilai jarak Euclid, maka menunjukkan semakin dekat objek-objek tersebut. Misalnya jarak Euclid antara Kabupaten Jembrana dengan Kabupaten Tabanan dalam biplot kekar yang mempunyai titik koordinat $(83.56,-1.81)$ dan (121.34, 71.50).

$$
\begin{aligned}
& d(x, y)=\sqrt{(83.56-121.34)^{2}+(-1.81-(-71.50))^{2}} \\
& \quad=79.27
\end{aligned}
$$

Hasil perhitungan menunjukkan, Kabupaten Jembrana dan Kabupaten Tabanan memiliki jarak Euclid yang besar sehingga kedua Kabupaten tersebut posisinya berjauhan.

Panjang vektor sebanding dengan keragaman peubah. Vektor yang panjang berarti keragaman peubahnya besar, sedangkan vektor yang pendek berarti keragaman peubahnya 
kecil. Misalnya akan dicari panjang vektor variabel APK SD/MI pada biplot kekar dengan titik koordinat $(0.016,0.019)$ yaitu:

$$
\|A P K S D\|=\sqrt{0.016^{2}+0.019^{2}}=0.025
$$

Dari perhitungan tersebut diketahui panjang vektor dari peubah APK SD/MI yaitu sebesar 0.025. Panjang vektor tiap variabel dalam biplot klasik dan biplot kekar ditampilkan pada Tabel 2.

Tabel 2. Panjang Vektor Tiap Variabel dalam Biplot Klasik dan Biplot Kekar

\begin{tabular}{|c|l|c|c|c|}
\hline \multirow{2}{*}{$\begin{array}{c}\text { Varia- } \\
\text { bel }\end{array}$} & \multicolumn{1}{|c|}{ Peubah } & \multicolumn{2}{|c|}{ Panjang Vektor } & \multirow{2}{*}{ Selisih } \\
\cline { 3 - 4 } & & $\begin{array}{c}\text { Biplot } \\
\text { Klasik }\end{array}$ & $\begin{array}{c}\text { Biplot } \\
\text { Kekar }\end{array}$ & \\
\hline Var 1 & APK SD/MI & 0.025 & 0.025 & 0.000 \\
\hline Var 2 & APK SMP/MTs & 0.091 & 0.086 & 0.005 \\
\hline Var 3 & APK SMA/MA & 0.021 & 0.021 & 0.000 \\
\hline Var 4 & APM SD/MI & 0.013 & 0.017 & -0.004 \\
\hline Var 5 & APM SMP/MTs & 0.070 & 0.064 & 0.006 \\
\hline Var 6 & APM SMA/MA & 0.041 & 0.020 & 0.021 \\
\hline Var 7 & R-S/G SD/MI & 0.025 & 0.031 & -0.006 \\
\hline Var 8 & $\begin{array}{l}\text { R-S/G } \\
\text { SMP/MTs }\end{array}$ & 0.029 & 0.036 & -0.007 \\
\hline Var 9 & R-S/G SMA/MA & 0.024 & 0.011 & 0.013 \\
\hline Var 10 & R-S/Sk SD/MI & 0.232 & 0.263 & -0.031 \\
\hline Var 11 & $\begin{array}{l}\text { R-S/Sk } \\
\text { SMP/MTs }\end{array}$ & 0.965 & 0.960 & 0.005 \\
\hline Var 12 & $\begin{array}{l}\text { R-S/Sk } \\
\text { SMA/MA }\end{array}$ & 0.995 & 0.994 & 0.001 \\
\hline Var 13 & R-G/Sk SD/MI & 0.011 & 0.010 & 0.001 \\
\hline Var 14 & $\begin{array}{l}\text { R-G/Sk } \\
\text { SMP/MTs }\end{array}$ & 0.033 & 0.028 & 0.005 \\
\hline Var 15 & $\begin{array}{l}\text { R-G/Sk } \\
\text { SMA/MA }\end{array}$ & 0.073 & 0.068 & 0.005 \\
\hline
\end{tabular}

Vektor peubah dalam biplot klasik sebagian besar lebih panjang dari biplot kekar sehingga keragaman pada biplot klasik lebih besar. Hal tersebut disebabkan oleh adanya pengamatan pencilan. Data pencilan yang letaknya dekat dengan peubah menyebabkan keragaman peubah lebih besar dari sebenarnya. Tabel tersebut menjelaskan pemerataan pendidikan pada Kabupaten/Kota di Bali, NTB dan NTT sangat beragam dalam hal R-S/Sk SMP/MTs dan R-S/Sk SMA/MA

Hasil analisis dalam biplot kekar, korelasi positif ditunjukkan oleh peubah APK dan APM dengan R-G/SK pada setiap jenjang pendidikan. Hal tersebut menunjukkan apabila APK dan APM meningkat pada setiap Kabupaten/Kota maka akan diikuti dengan meningkatnya $\mathrm{R}$ G/Sk. Sedangkan kerolasi negatif ditunjukan oleh APK dan APM dengan R-S/G pada jenjang pendidikan, yang menunjukkan meningkatnya APK dan APM SD/MI dan SMA/MA akan diikuti dengan menurunnya R-S/G.

Dalam analisis biplot, kedekatan antara objek dengan peubah dapat diketahui dengan menentukan nilai proyeksi. Nilai proyeksi objek dengan peubah $\leq 1$, dapat dikatakan peubah tersebut merupakan peubah penciri dari objek. Misalnya dicari nilai proyeksi antara Kabupaten Jembrana dengan peubah APK SD/MI dalam biplot kekar yaitu:

$$
\begin{aligned}
\text { Proy }_{\mathrm{J}} \mathrm{APK} & =\frac{(0.016 \times 83.56)+(0.019 \times-1.18)}{\sqrt{83.56^{2}+-1.18^{2}}} \\
& =0.016 \\
\operatorname{Cos} \theta & =\frac{0.016}{\sqrt{00.016^{2}+0.019^{2}}}=0.631
\end{aligned}
$$

Berdasarkan hasil perhitungan, nilai proyeksi antara Kabupaten Jembrana dengan peubah APK SD/MI sebesar 0.631. Dengan perhitungan yang sama, nilai proyeksi antara Kabupaten Jembrana dengan peubah APK SMP/MTs sebesar 0.171 dan dengan peubah APK SMA/MA sebesar 0.708. Nilai proyeksi antara Kabupaten Jembrana dengan peubah APK SD/MI-SMA/MA menunjukan $\leq 1$, yang berarti APK SD/MI-SMA/MA merupakan peubah penciri dari Kabupaten Jembrana.

Pemerataan pendidikan dilihat dengan menentukan rata-rata dari nilai proyeksi objek dengan peubah. Nilai proyeksi tiap Kabupaten/Kota yang lebih besar atau sama dengan rata-rata, diartikan bahwa Kabupaten/Kota tersebut merata pada indikator pendidikan tersebut. Sebaliknya apabila nilai proyeksi yang kurang dari rata-rata maka dapat diartikan Kabupaten/Kota tersebut belum merata pada indikator pendidikan tersebut. Peubah R-S/Sk SMP/MTs dan R-S/Sk SMA/MA merupakan indikator dominan terhadap pemerataan pendidikan pada Kabupaten/Kota di Bali, NTB dan NTT tahun 2012/2013. Rata-rata dari nilai proyeksi objek 
dengan peubah pada peubah R-S/Sk SMP/MTs dan R-S/Sk SMA/MA ditampilkan pada Tabel 3.

Tabel 3. Rata-rata Peubah R-S/Sk SMP/MTs dan R-S/Sk SMA/MA

\begin{tabular}{|c|c|c|c|}
\hline Objek & $\begin{array}{c}\text { R-S/Sk } \\
\text { SMP/MTs }\end{array}$ & $\begin{array}{c}\text { R-S/Sk } \\
\text { SMA/MA }\end{array}$ & Rata-rata \\
\hline 1 & 0.872 & 0.512 & 0.692 \\
\hline 2 & 1.000 & 0.027 & 0.514 \\
\hline 3 & 0.817 & 0.599 & 0.708 \\
\hline 4 & 0.924 & 0.406 & 0.665 \\
\hline 5 & 0.705 & 0.728 & 0.716 \\
\hline 6 & 0.417 & -0.897 & -0.240 \\
\hline 7 & 0.030 & 1.000 & 0.515 \\
\hline 8 & 0.722 & -0.672 & 0.025 \\
\hline 9 & 0.923 & 0.410 & 0.666 \\
\hline 10 & 0.622 & -0.766 & -0.072 \\
\hline 11 & -0.929 & -0.394 & -0.662 \\
\hline 12 & 0.293 & -0.948 & -0.327 \\
\hline 13 & 0.651 & 0.776 & 0.714 \\
\hline 14 & 0.817 & -0.554 & 0.132 \\
\hline 15 & 1.000 & 0.008 & 0.504 \\
\hline 16 & -0.730 & -0.703 & -0.716 \\
\hline 17 & 0.892 & -0.427 & 0.233 \\
\hline 18 & 0.970 & 0.271 & 0.620 \\
\hline 19 & 0.600 & 0.816 & 0.708 \\
\hline 20 & -0.858 & -0.537 & -0.697 \\
\hline 21 & -0.935 & -0.380 & -0.657 \\
\hline 22 & -0.901 & -0.458 & -0.680 \\
\hline 23 & 0.201 & 0.985 & 0.593 \\
\hline 24 & -0.833 & -0.575 & -0.704 \\
\hline 25 & -0.794 & -0.630 & -0.712 \\
\hline 26 & -0.976 & 0.190 & -0.393 \\
\hline 27 & -0.930 & -0.391 & -0.661 \\
\hline 28 & -0.938 & -0.371 & -0.655 \\
\hline 29 & 0.233 & 0.978 & 0.606 \\
\hline 30 & -0.239 & 0.964 & 0.363 \\
\hline 31 & -0.990 & 0.116 & -0.437 \\
\hline 32 & -0.845 & -0.557 & -0.701 \\
\hline 33 & -0.970 & -0.271 & -0.620 \\
\hline 34 & -0.483 & -0.888 & -0.686 \\
\hline 35 & -0.976 & 0.193 & -0.392 \\
\hline 36 & -0.985 & -0.197 & -0.591 \\
\hline 37 & -0.887 & -0.486 & -0.686 \\
\hline 38 & -0.675 & -0.755 & -0.715 \\
\hline 39 & -0.561 & 0.813 & 0.126 \\
\hline 40 & 0.997 & -0.050 & 0.474 \\
\hline Rata-rata & -0.069 & -0.053 & -0.061 \\
\hline
\end{tabular}

Kabupaten/Kota yang memiliki pendidikan yang merata pada indikator R-S/Sk SMP/MTs yaitu Kabupaten Jembrana, Tabanan, Badung, Gianyar, Bangli, Buleleng, Kota Denpasar, Lombok Barat, Lombok Timur, Dompu, Bima, Lombok Utara, Kota Mataram dan Kota Kupang. Sedangkan pendidikan yang merata pada indikator R-S/Sk SMA/MA terjadi pada Kabupaten Klungkung, Karangasem, Sumbawa, Kota Bima, Timor Tengah Selatan, Alor, Sikka, Ende, Ngada, Sumba Tengah dan Sabu Raijua.

\section{KESIMPULAN}

Berdasarkan pembahasan yang telah dipaparkan, maka dapat disimpulkan bahwa:

1. Metode yang lebih baik digunakan dalam menentukan pemerataan pendidikan pada setiap Kabupaten/Kota di Bali, NTB dan NTT adalah analisis biplot kekar, dengan ukuran kesesuaian biplot kekar sebesar 90,64\% dan biplot klasik sebesar 83,62\% dari keseluruhan data dalam dimensi dua pada pengamatan yang mengandung pencilan.

2. Indikator pendidikan yang dominan terhadap pemerataan pendidikan pada Kabupaten/Kota di Bali, NTB dan NTT dengan menggunakan biplot kekar adalah R-S/Sk SMP/MTs dan R-S/Sk SMA/MA. Kabupaten/Kota yang memiliki pendidikan yang merata pada indikator R-S/Sk SMP/MTs dan R-S/Sk SMA/MA yaitu Kabupaten Jembrana, Tabanan, Badung, Gianyar, Klungkung, Karangasem, Buleleng, Kota Denpasar, Sumbawa, Dompu, Bima, Lombok Utara, Kota Mataram, Kota Bima, Timor Tengah Selatan, Sikka, Ende, Sabu Raijua dan Kota Kupang.. 


\section{DAFTAR PUSTAKA}

[1] Jolliffe, I.T., 2002. Principal Component Analysis. 2nd ed. New York: SpringerVerlag.

[2] Filzmoser, P., 2004. A Multivariate Outlier Detection Method. Austria: Departement of Statistics and Probability Theory.

[3] Johnson, R.A. \& Wichern, D.W., 2007. Applied Multivariate Statistical Analysis. 6th ed. New Jersey: Pearson Prentice Hall.

[4] Rousseeuw, P.J. \& Driessen, K.V., 1999. A Fast Algorithm for the Minimum Covariance Determinant Estimator. Technometrics, 41, pp.212 - 223.

[5] Hawkins, D.M., Liu, L. \& Young, S.S., 2001. Robust Singular Value Decomposition. National Institute of Statistical Sciences, 122, pp.1-12.

[6] BPS, 2013. Statistika Pendidikan 2013. Jakarta: Badan Pusat Statistika Republik Indonesia. 